\title{
A prática como lócus de produção de saberes: vozes de professores sobre formação inicial e práticas escolares cotidianas
}

\author{
Sônia Maria Soares de Oliveiraidi \\ Secretaria de Educação do Estado do Ceará, Fortaleza, CE, Brasil \\ Fátima Maria Leitão Araújoi®i] \\ Universidade Estadual do Ceará, Fortaleza, CE, Brasil \\ Carlos Diogo Mendonça da Silvaiii(i) \\ Universidade Estadual do Ceará, Fortaleza, CE, Brasil
}

\begin{abstract}
Resumo
O presente artigo é um excerto de uma pesquisa mais ampla, na qual se investigam os saberes e as práticas de professores da educação básica. A escrita foca a prática docente, entendendo-a como lócus importante de produção e ressignificação de saberes. Analisa-se a complexidade dos saberes da prática professoral e como o cotidiano forja tais saberes. Neste sentido, as reflexões aqui suscitadas vão ao encontro da perspectiva que vê a docência como uma prática profissional situada, sendo o professor um sujeito ativo que ressignifica e intervém nos fazeres de sua profissão. Por meio de depoimentos de professores de História do ensino médio público da cidade de Maranguape, no estado do Ceará, foi possível aferir que o fazer diário do ofício docente constitui lócus de formação incontestável para a definição da identidade profissional docente, revelando as lacunas deixadas pela formação inicial, mostrando, assim, o caráter formador da prática do ato de ensinar.
\end{abstract}

\section{Palavras-chave}

Saberes docentes. Formação inicial. Saberes da prática.

\section{Practice as locus of knowledge production: teacher's voices about initial}

\author{
training and everyday school practices
}

\begin{abstract}
The present article is an excerpt of a broader research, in which we investigate the knowledge and practices of teachers of basic education. The writing focuses on teaching practice, understanding it as an important locus of production and resignification of knowledge. We analyzed the complexity of the knowledge of teacher practice and how the everyday forges such knowledge. In this sense, the reflections that we bring in this writing meet the perspective that sees teaching as a localized professional practice, with the teacher as an active subject who resignifies and intervenes in the actions of their profession. Through testimony of History teachers from public high schools in the city of Maranguape, in the state of Ceará, it was possible to verify that the daily making of the teaching profession constitutes an undeniable locus of training for the definition of the professional
\end{abstract}

Educ. Form., Fortaleza, v. 6, n. 1, e2885, jan./abr. 2021

DOI: https://doi.org/10.25053/redufor.v6i16jan/abr.2885

https://revistas.uece.br/index.php/redufor/index 
identity of the teacher, revealing the gaps left by the initial training, thus revealing the formative character of the practice of the act of teaching.

\author{
Keywords \\ Teachers' knowledge. Initial training. Knowledge of practice.
}

Práctica como lugar de producción de conocimiento: las voces de los maestros sobre la formación inicial y las prácticas escolares cotidianas

\begin{abstract}
Resumen
El presente artículo es un extracto de una investigación más amplia, en la que se investigan los saberes y las prácticas de profesores de la educación básica. La escritura enfoca la práctica docente, entendiéndola como lócus importante de producción y resignificación de saberes. Se analiza la complejidad de los saberes de la práctica docente y cómo el cotidiano forja tales saberes. En este sentido, las reflexiones aquí escritas van al encuentro de la perspectiva que ve la docencia como una práctica profesional situada, siendo el profesor un sujeto activo que resignifica e interviene en los hechos de su profesión, siendo, por lo tanto, sujeto activo de su práctica. Por medio de testimonios de profesores de Historia de la enseñanza media pública de la ciudad de Maranguape, en el estado de Ceará, Brasil, ha sido posible aferir que el hacer diario del oficio docente constituye un lócus de formación incontestable para la definición de la identidad profesional docente, revelando las lagunas de la formación inicial, indicando, así, el carácter formador de la práctica del acto de enseñanza.
\end{abstract}

Palabras clave

Saberes docentes. Formación inicial. Saberes de la práctica.

\title{
1 Introdução
}

O presente artigo constitui um excerto de uma pesquisa mais ampla ${ }^{1}$, na qual investigamos os saberes e as práticas de professores da educação básica, notadamente do ensino médio, da rede pública estadual da cidade de Maranguape, localizada na região metropolitana de Fortaleza, no estado do Ceará. A escrita foca a prática docente, entendendo-a como lócus importante de produção e ressignificação de saberes.

Partimos da perspectiva de que os paradigmas que hierarquizam saberes, que promovem a dicotomia entre teoria e prática e que consideram o professor como mero transmissor de conteúdos se tornaram obsoletos ante a complexidade que constitui a

\footnotetext{
1 Pesquisa que resultou em dissertação apresentada ao Programa de Pós-Graduação em Educação da Universidade Estadual do Ceará (ỦECE), intitulada Formação de professores e ensino de História da África e cultura afro-brasileira e africana: saberes e práticas (OLIVEIRA, 2016).
}

Educ. Form., Fortaleza, v. 6, n. 1, e2885, jan./abr. 2021

DOI: https://doi.org/10.25053/redufor.v6i16jan/abr.2885

https://revistas.uece.br/index.php/redufor/index 
docência. Nesse sentido, as abordagens em voga atualmente consideram o professor como sujeito ativo no ser e fazer-se no chão da sala de aula e nos diversos espaços de sua ação educacional.

Os saberes da prática professoral, forjados no cotidiano, são tão complexos e importantes que ultrapassam os limites da formação inicial. Os cursos de formação de professores ainda são lacunares no que diz respeito à efetivação de uma formação que leve em conta o repertório de saberes oriundos da prática e que são essenciais à constituição do ser professor. Nesse sentido, as reflexões que trazemos nesta escrita vão ao encontro da perspectiva que vê a docência como uma prática profissional situada, sendo o professor um sujeito ativo e que se encontra em contínuo processo de ressignificação de seus saberes e práticas, sendo, portanto, sujeito ativo de sua prática.

Com o intento de desvelar as percepções de docentes sobre os saberes adquiridos no chão da sala de aula, damos voz aos professores do ensino médio que realizam suas experiências em escolas da rede pública estadual do Ceará, na cidade de Maranguape. Os referidos sujeitos são identificados por nome fictícios, assegurando o anonimato de nossos colaboradores. Ratificamos nossas reflexões teóricas por meio de vozes que nos explicitam como ocorre a prática docente. Por conseguinte, inquirimos como nossos sujeitos concebem sua prática e a influência que a formação acadêmica exerceu/exerce sobre esta.

\section{A ação pedagógica e os saberes da prática}

A atual sociedade do conhecimento traz consigo indagações complexas a que 0 velho modelo de ciência iluminista e cartesiano não consegue mais responder. Nesse contexto, vem se processando o ressignificar da profissão docente e sobretudo dos saberes que a constituem. Para Veiga e D'Ávila (2008), os paradigmas que consideram os saberes como hierarquicamente estabelecidos estão sendo postos em xeque. Desse modo, afirmam os autores que "[...] há a necessidade de destacar que o exercício da docência envolve saberes específicos, os saberes pedagógicos e os saberes construídos nos espaços da experiência" (VEIGA; D’ÁVILA, 2008, p. 20). Assim, de 
acordo com o modelo da racionalidade técnica ${ }^{2}$, os professores são concebidos como meros executores de tarefas preestabelecidas, reprodutores de conhecimentos produzidos por outrem, concepção essa que desconsidera a subjetividade inerente ao processo ensino-aprendizagem, bem como não os percebendo como sujeitos produtores de conhecimentos.

Em contraposição ao paradigma mencionado, a categoria saber docente passa a predominar na maioria das pesquisas relacionadas à educação na atualidade. Corroborando Gauthier et al. (1998, p. 28), é necessário afirmar que "[...] de fato é muito mais pertinente conceber o ensino como a mobilização de vários saberes que formam uma espécie de reservatório, no qual o professor se abastece para responder às exigências do ensino". Em tal perspectiva, podemos identificar o que o referido pesquisador chama de "reservatório de saberes" dos professores, os quais são mobilizados no exercício da docência, quais sejam: o saber disciplinar, que é produzido pelos pesquisadores e cientistas nas diversas disciplinas científicas; o saber curricular, que sofre as modificações para se adaptar aos programas escolares; o saber das ciências da educação, aquele adquirido durante a formação e o trabalho; o saber da tradição pedagógica, adquirido antes mesmo de se ter feito um curso de formação; o saber experiencial, elaborado ao longo do tempo de carreira; e o saber da ação pedagógica, aquele constituído no ato de ensinar. A relação dos docentes com os saberes, portanto, não se reduz à mera transmissão de conhecimentos já constituídos, outrossim, o professor deve ser visto "[...] como profissional dotado de razão, um ator que toma decisões, faz julgamentos, no contexto complexo e incerto da sala de aula. Suas ações são guiadas por pensamentos, julgamentos e decisões" (BORGES, 2003, p. 65), pois é ele um ator que toma decisões, faz julgamentos, no contexto complexo e incerto da sala de aula.

A tentativa de superar a relação linear e mecânica entre o conhecimento técnico-científico e a prática na sala de aula suscitou o surgimento de vários estudos e pesquisas com o objetivo de realizar críticas à racionalidade técnica. A ampliação desses estudos no âmbito da formação docente ocorreu de forma mais efetiva a partir dos anos 80 do século $\mathrm{XX}$, intensificando-se ao longo das quase duas décadas do século XXI. O

2 O paradigma da racionalidade técnica é uma concepção epistemológica da prática herdada do positivismo, na qual a atividade profissional é instrumental, dirigida para a solução de problemas mediante a aplicação rigorosa de teorias e técnicas científicas.

Educ. Form., Fortaleza, v. 6, n. 1, e2885, jan./abr. 2021

DOI: https://doi.org/10.25053/redufor.v6i16jan/abr.2885 
empreendimento que visa extrapolar os limites e insuficiências dessa concepção levam à busca de novos instrumentos teóricos, capazes de dar conta da complexidade dos fenômenos e ações inerentes à produção e à mobilização de saberes na e para a docência.

Portanto, o paradigma da racionalidade técnica teve suas bases questionadas, pois trabalhava com a concepção de professor como um instrumento de transmissão de saberes produzidos por outros (MONTEIRO, 2007). Em razão disso, Tardif, Lessard e Lahaye (1991) chamam a atenção para o fato de que o saber docente é plural, estratégico, constituindo um amálgama, mais ou menos coerente, de saberes oriundos da formação profissional, dos saberes das disciplinas, dos currículos e da experiência. Essa visão atribui ao professor o status de profissional dotado de autonomia e supera pois, a concepção de que o professor é um "idiota cognitivo", expressão usada por Tardif (1999). Os saberes profissionais dos professores são temporais, plurais e heterogêneos, personalizados e situados, carregam as marcas do ser humano e provêm inclusive de sua história de vida e de sua cultura escolar anterior. Para Araújo e Moreira Junior (2012, p. 121), "[...] o professor vai construindo saberes e experiências, fruto da conciliação do amálgama de saberes constitutivos da cultura docente e dos fatores externos à sala de aula". Essas concepções são importantes para a compreensão dos saberes produzidos pela ação docente, os saberes da experiência, forjados no "chão da sala de aula", sobretudo os saberes provenientes da prática e da ação pedagógica.

Como diria Certeau (1994, p. 18-19), interessam-nos "[...] as astúcias táticas das práticas ordinárias [...], pois o dia-a-dia [sic] se acha semeado de maravilhas, devido à liberdade gazeteira das práticas". A afirmação de Certeau (1994) é pertinente, ratificando o já mencionado processo de ressignificação da profissão docente, essa vista como um conjunto de funções múltiplas e complexas que ultrapassam a tarefa de ministrar aulas. $\mathrm{Na}$ dinâmica presente no chão da sala de aula, ocorre a interligação entre saberes e práticas.

Dessa forma, defendemos a docência como uma prática profissional situada, complexa e socialmente produzida e o professor como um sujeito ativo que ressignifica e intervém nos fazeres de sua profissão, sendo, portanto, sujeito ativo da prática. Assim, para D’Ávila e Sonneville (2008), faz-se necessária uma nova epistemologia da prática, que reconheça os saberes oriundos, mobilizados e (re)construídos nas práticas 
docentes, visto que os professores produzem, transformam e ressignificam os saberes no ato de ensinar, sendo, portanto, a prática docente um lócus de produção de saberes.

Sendo assim, não se pode negar a subjetividade inerente aos saberes que estes constituem e mobilizam em seu dia a dia em sala de aula. Entendemos que o trabalho do professor, como atividade humana, é constituído de particularidades e se faz necessário "[...] compreender o que esses trabalhadores que lecionam profissionalmente nas escolas são, fazem e sabem [...]" (ALVES, 2010, p. 37). É necessário entender a natureza e a especificidade do ensino e os aspectos mais amplos do fenômeno educativo, isto é, a natureza da docência. Assim, a caracterização da natureza do trabalho pedagógico e consequentemente dos saberes que o constituem é essencial para delinear com mais precisão o exercício profissional do magistério. De fato, "[...] aquilo que chamamos de 'saber dos professores' ou 'saber-ensinar' deve ser considerado e analisado em função dos tipos de ação presentes na prática" (TARDIF, 2012, p. 177-178).

A docência é um trabalho interativo e seu objeto é humano, o que acaba por modificar a natureza do trabalho e a própria natureza do trabalhador, no caso da profissão professor, uma vez que não é só o trabalho com o outro, mas, acima de tudo, um trabalho sobre o outro.

\begin{abstract}
Quanto ao trabalho sobre e com os seres humanos, esse leva antes de tudo a relações entre pessoas, com todas as sutilezas que caracterizam as relações humanas [...] negociação, controle, persuasão, sedução, promessa, etc. Esse trabalho sobre o humano evoca atividades como: instruir, supervisar, servir, ajudar, entreter, curar, cuidar controlar etc. (TARDIF; LESSARD, 2007, p. 33).
\end{abstract}

Além dos aspectos mencionados anteriormente, a docência envolve também questões de conflitos e valores, situações com as quais os professores se deparam e que têm de resolver. Assim, as práticas cotidianas dos atores escolares são marcadas por interações dinâmicas e experiências vivas. A docência é uma construção social, ela se caracteriza por possuir aspectos variáveis, ou seja, é uma atividade heterogênea que possui um duplo aspecto: determinado e contingente simultaneamente, residindo aí sua complexidade, bem como a dos saberes necessários para a sua realização.

Ainda sobre a atividade docente em seu cotidiano, é importante analisarmos o lócus, o lugar concreto onde esta se realiza, no caso a escola. Como a maioria das organizações sociais, a escola é marcada pela burocratização do trabalho de seus agentes, dessa forma o contexto escolar constitui um ambiente de contingência para o 
trabalho dos docentes. Sendo o espaço da sala de aula lugar onde ainda por excelência se dá a atividade do professor diariamente, é um local sujeito a normatizações próprias do sistema educacional, porém é, acima de tudo, um micromundo repleto de possibilidades, uma vez que a docência e o processo ensino-aprendizagem são mais do que uma mera transmissão de conteúdos didatizados. Assim, o professor sujeito/ator que produz e mobiliza saberes tem diante de si classes repletas de alunos/sujeitos/atores. Há, portanto, algo de específico na ação docente, um conjunto de comportamentos, conhecimentos, destrezas, atitudes e valores que constituem a especificidade de ser professor. Por isso, urge a necessidade de se repensarem os programas de formação de professores.

Dessa forma, Gómez (1995, p. 102) defende que "[...] o professor intervém num meio ecológico complexo, num cenário psicossocial vivo e mutável, definido pela interação simultânea de múltiplos fatores e condições". Assim, estabelece um diálogo reflexivo com a situação problemática complexa, o que requer um leque de saberes a serem mobilizados constantemente. Tais saberes assemelham-se muito mais a uma teia do que a uma linha uniforme, uma vez que "[...] a reflexão não é um conhecimento puro, mas sim um conhecimento contaminado pelas contingências que rodeiam e impregnam a própria experiência vital" (GÓMEZ, 1995, p. 103). Entender toda essa complexidade por meio de uma realidade específica é o desafio desta escrita. Para tanto, apresentamos o percurso metodológico que nos levou às vozes de professores que desnudam suas práticas.

\section{Percurso metodológico: caminhos trilhados em busca das vozes}

Um paradigma consiste num conjunto de crenças e valores que norteiam a investigação, e toda investigação tem implícita uma orientação teórica, portanto os fundamentos teóricos que embasam esta pesquisa são os que se ancoram no paradigma interpretativo, de acordo com a classificação de Alves-Mazzotti (1996). Segundo ainda essa autora, tal paradigma tem como característica fundamental a interpretação do fenômeno pesquisado com base na visão dos agentes envolvidos em um contexto específico. 
Dentro do paradigma supracitado, a presente pesquisa realizou-se tendo como base uma abordagem qualitativa. Nesse tipo de abordagem, o pesquisador prima pela obtenção de dados descritivos mediante contato direto com a situação objeto de estudo. Para Minayo (2013), a pesquisa qualitativa trabalha com o universo de significados, motivos, aspirações, crenças, valores e atitudes, o que corresponde a um espaço mais profundo das relações, dos processos e dos fenômenos que não podem ser reduzidos à operacionalização de variáveis.

No que se refere ao método, entendemos que essa questão vai além da técnica, o método imbrica-se em um contexto epistemológico mais amplo e requer análises mais complexas, sobretudo de sua relação com outros aspectos da pesquisa. Para Nóbrega-Therrien, Farias e Sales (2010), os métodos são mais abrangentes do que as técnicas; esses não devem ser confundidos, pois o método, segundo os autores, dentro de um ponto de vista epistemológico, deve ser entendido como uma forma de abordar a realidade, isto é, como um arcabouço conceitual usado pelo pesquisador.

Optamos por fazer uso da história oral por entendermos ser condizente com a proposição da pesquisa, haja vista a necessidade da apreensão do fazer-se e ser professor por meio das próprias falas desses sujeitos. Assim, em suas narrativas, é possível o entendimento de como eles vão se apropriando e se constituindo como docentes, visto que a formação é um processo contínuo, proveniente não só das instituições formais, mas do amálgama de conhecimentos forjados durante todos os processos formativos dos sujeitos.

As entrevistas, principal técnica para a coleta de dados da investigação, foram realizadas individualmente e a partir de um roteiro semiestruturado, pois entendemos que os campos da realidade social podem ter diferentes versões a partir da memória particular que determinados atores sociais têm do passado, o que assinala mais uma característica importante da memória. Nessa perspectiva, é preciso conhecer quem faz lembrar, pois os grupos que acionam esse processo o fazem a partir de um lugar determinado na grade sociocultural, com questões próprias sobre tal passado.

Além do recurso da oralidade, foram consultados documentos relacionados às políticas e gestão educacionais do estado do Ceará, bem como os produzidos pelos próprios professores, como diários de classe, planos de aula, dentre outros. Foi selecionado um professor de História de cada escola da rede estadual da cidade, onde 
existem sete escolas do ensino médio. Em nosso entender, um sujeito de cada unidade nos daria uma visão bastante significativa da realidade investigada. Nesse sentido, após visitar as escolas e entrar em contato com os docentes, conseguimos a adesão de sete professores para a participação em nossa pesquisa, seguindo assim com a assinatura do Termo de Livre Consentimento, no qual estavam explicitados os pormenores da pesquisa.

A partir de tais procedimentos, trilhamos o caminho para responder ao nosso problema de pesquisa e de alguma forma traçar um panorama de como os professores constituíram seus saberes, sobretudo os saberes da prática, e de que forma os mobilizam em seus cotidianos em sala de aula.

\title{
4 Formação acadêmica e prática pedagógica: vozes do cotidiano
}

Nesta seção, apresentamos as falas de professores que participaram como sujeitos em nossa investigação. Procuramos entender como nossos narradores concebem sua prática e a influência que a formação acadêmica exerceu/exerce sobre esta. Abaixo apresentamos os relatos, que nos fornecem a visão que trazem sobre seus processos formativos.

\begin{abstract}
Oh, sinceramente eu acho que a gente começa a aprender mais quando tá colocando em prática, quando diz assim: 'Ah, tu vai ser professora', a gente fica, primeiro de tudo, a gente entra na universidade, a gente vê que nada do que a gente tá aprendendo é pra ser colocado em prática, parece que a gente tá o tempo todo vivendo na teoria, vivendo o tempo todo na teoria. Quando a gente pensa que vai pra dentro, eu vou entrar na sala de aula, aí, sim, aí eu vou ter que colocar em prática um monte de coisa, e aí? Eu acho que existe uma distância muito grande entre a formação acadêmica e a sala de aula [...]. Eu vejo um distanciamento muito grande e assim, na especialização, eu escolhi Metodologias do Ensino justamente por conta disso [...]. Eu procurei um curso de Metodologia que era justamente pra - enfeitar essa situação, eu acho, eu achava assim que - eu vou aprender maneiras de como trabalhar determinado assunto na sala de aula [...]. (Professora Henriqueta Galeno) ${ }^{3}$.
\end{abstract}

Aqui vemos que a professora é bem clara ao dizer que procurou um curso de especialização em Metodologias do Ensino para aprender, segundo ela, maneiras de "passar" o conteúdo, no entanto chega à conclusão de que a prática cotidiana é muito mais eficaz nesse sentido, revelando o que vínhamos discutindo até então nos itens

3 Optamos por nomear nossos sujeitos fazendo uma homenagem a figuras históricas de relevância para a Educação de modo geral e para o Ceará de forma mais específica.

Educ. Form., Fortaleza, v. 6, n. 1, e2885, jan./abr. 2021

DOI: https://doi.org/10.25053/redufor.v6i16jan/abr.2885

https://revistas.uece.br/index.php/redufor/index ISSN: 2448-3583 
anteriores, que a prática é um lócus de produção de saberes e de que temos de pensar em uma nova epistemologia da prática, que seja inclusive incorporada aos programas de formação de professores, que, na maioria das vezes, têm seu foco em aspectos técnicos e metodológicos, desprezando os saberes e possibilidades provenientes do fazer pedagógico, fazer que se constrói principalmente no cotidiano, no ato mesmo de ensinar. Opinião semelhante tem outra professora ao se referir à formação e à prática. Vejamos:

\begin{abstract}
A formação acadêmica não te dá essa base, ela não te prepara pra sala de aula; mesmo a licenciatura, ela não te prepara pra sala de aula. Porque a sala de aula você só vai conseguir saber o que é quando entrar, sabe? Não é uma experiência de um estágio, porque no estágio é uma coisa, no estágio tu vai... Como eu, fiz o estágio em uma escola pública, foi uma semana, isso me deu uma visão do que era a sala de aula? Não, não dá; eu só vou saber isso quando eu tiver lá constantemente, todo dia, as oito horas por dia. (Professora Bárbara de Alencar).
\end{abstract}

Nesse caso, insistimos na pergunta e colocamos a seguinte questão: se a formação acadêmica não dá essa base, como isso se processa? E a professora assim nos responde:

Tu constrói isso no cotidiano, no dia a dia; no dia a dia, tu vai aprendendo a lidar com o aluno, vai aprendendo que dá pra negociar algumas coisas em sala, outras num dá pra negociar; tem dias que você tem que impor; tem dias que você tem que recuar, sabe [...], tu vai aprendendo a lidar com gente! (Professora Bárbara de Alencar).

Em relação a esse caso, Therrien e Carvalho (2009) nos falam de aspectos necessários à compreensão dos elementos subjacentes à práxis pedagógica, dos saberes forjados na prática educativa e da complexidade da ação situada em contextos de interação e de intersubjetividades do professor sujeito da ação docente. Para os autores, os saberes docentes são constructos sociais produzidos pela reflexão, sendo, portanto, constitutivos e construtores da racionalidade pedagógica. Nesse caso, racionalidade pedagógica pode ser definida como concepção ou conjunto de saberes que o professor constrói e articula continuamente acerca das categorias centrais do seu trabalho docente. Nesse mesmo sentido, Tardif (2012) enfatiza a necessidade de se estudar o conjunto de saberes utilizados pelos profissionais em seu espaço de trabalho cotidiano para desempenhar todas as suas tarefas.

Educ. Form., Fortaleza, v. 6, n. 1, e2885, jan./abr. 2021

DOI: https://doi.org/10.25053/redufor.v6i16jan/abr.2885

https://revistas.uece.br/index.php/redufor/index 
Outra colaboradora da pesquisa é mais enfática e destaca que seu curso de graduação tinha um caráter mais voltado para formar pesquisador, e não professor. Interessante notar como ainda há essa separação em muitas instituições, não se considerando o professor como um pesquisador, reflexo talvez de um paradigma que hierarquiza o conhecimento. Assim, ao questionarmos sobre sua formação inicial e a influência que esta teve para sua prática pedagógica, a professora assim se pronuncia:

[...] a prática em si eu acho que é mais embasada no que eu adquiri como professora do que como aluna de graduação, porque, como eu te disse, a minha graduação era muito voltada pra pesquisa e pouco voltada pro ensino, então não extraí tanta coisa assim pra trazer pra sala de aula. (Professora Edite Braga).

A fala da professora corrobora a concepção de Schön (2000), ao afirmar que a prática é produtora de saberes e sentidos que se encontram apoiados em uma racionalidade, não a racionalidade técnica, por essa não possibilitar uma formação reflexiva para o enfrentamento de novas e diversas situações da vida real, o que gera também uma crise de confiança nos profissionais por parte da sociedade. O profissional, e nesse caso o professor, é um sujeito epistêmico em constante conversação com sua situação de trabalho. Assim, essa postura reflexiva (re)significa a prática e promove a construção de saberes na ação, sendo, portanto, essa a característica principal da proposta de uma nova racionalidade, uma racionalidade construtivista.

O próximo professor relata as características de seu curso de graduação:

\begin{abstract}
No meu período, de 2002 a 2007, eu acho que pecava um pouco a parte prática, essa parte de vivência em sala de aula, porque a gente é professor, e professor é também pesquisador, tudo bem, mas no meu período eles pecavam um pouquinho nisso. A gente tinha sempre aquelas disciplinas de conteúdos históricos, daqueles períodos tradicionais, daquela divisão tradicional ainda francesa baseada na historiografia francesa, que é: Pré-História, História Antiga, Medieval, Moderna e Contemporânea; o curso de História no meu período seguia essa visão tradicional francesa, dos historiadores franceses, que acho ainda é o que predomina muito hoje ainda. Então, a gente via sempre essas teorias, só que a gente ia pra teoria, pra parte prática, só no último ano que a gente ia pra sala de aula viver essa prática. Eu acho que é extremamente negativo. Eu acho que a gente tem que tentar, no meu ponto de vista, conciliar esse conteúdo sempre com a sala de aula. E, pelo que eu andei percebendo, na nova grade curricular do curso de História da UFC [Universidade Federal do Ceará], eles já tão tentando fazer isso [...]. Então, eu acho que pecou nesse sentido. (Professor Lourenço Filho).
\end{abstract}

O discurso seguinte ratifica os dois anteriores, até porque os professores tiveram sua formação na mesma instituição, este, porém, ressalta que o fato de ter começado a

Educ. Form., Fortaleza, v. 6, n. 1, e2885, jan./abr. 2021

DOI: https://doi.org/10.25053/redufor.v6i16jan/abr.2885

https://revistas.uece.br/index.php/redufor/index 
a sua práxis, revelando o caráter formador da prática.

\begin{abstract}
Esse era um debate que a gente sempre tinha lá; tinha uma frasezinha recorrente que todo mundo dizia: 'Se você quer ser pesquisador, vem pra UFC. Se você quer ser professor, você vai pra UECE'. Então, desde cedo havia esse estímulo. Então, as disciplinas de pesquisa elas sempre vinham primeiro. No primeiro semestre, a gente tinha essa disciplina que era Introdução à Prática Profissional do Historiador, e esse professor não nos ensinou um " $A$ " relacionado à atuação do professor em sala de aula, sempre era a atuação do historiador no campo de pesquisa, como pesquisador. Então, não havia uma preocupação da construção de bons profissionais em sala de aula, era sempre um menor. Eu tenho o pesquisador que é o maior, aquele que vai estudar, aquele que vai criar o livro, e o professor ele vai falar aquilo que o cara já teve o trabalho de pesquisar. Óbvio, quando eu tava saindo nesse processo de quatro anos, começou um debate sério dentro de reflexão curricular e houve mudanças importantes. $\mathrm{Na}$ minha época, a gente fazia dois estágios, era em fundamental e um no médio, agora, pelo que eu vi do currículo novo que eles implementaram logo quando eu tava saindo, ali em 2009, já tinha uma outra carga de ensino pedagógico. A área de ensino me parece nesse momento ter ganhado papel mais relevante dentro do Departamento de História da UFC [...]. Consigo perceber esse crescimento do ensino, mas o ensino ainda em segundo plano; o professor é a forma pejorativa, que eu chamo historiador; historiador é historiador, e aí fica aquela questão de que o historiador é aquele que, ao mesmo tempo, pesquisa e ensina. Mas, por outro lado, a maioria dos nossos professores não tem experiência em sala de aula no ensino fundamental e médio; estão lá dando aula pra tentar ajudar o professor em formação a dar aula no ensino fundamental e médio como? Não sei como é que eles acham que vão conseguir isso [...]. Como é que eu posso falar de algo que eu não experimentei? Óbvio, tem o livro, tem o estudo, sim, mas a gente sabe que a realidade que é mostrada nos livros é um pouco distante da realidade prática. (Professor Moreira de Sousa).
\end{abstract}

Quando questionamos quais as implicações da ênfase na pesquisa na sua formação inicial, ele assim se posiciona:

\begin{abstract}
Teve um lado muito positivo, que foi essa preocupação constante com a pesquisa. Então, durante todo o meu processo em sala de aula, eu tento aplicar, junto aos meus alunos e durante meu processo de planejamento, 0 exercício de pesquisa [...]. Por outro lado, eu acho que tem algo negativo, sim, porque, mesmo estando nesse processo dialógico, nesse processo de práxis, eu já tando em sala de aula e podendo tá na universidade, eu sinto que as reflexões não eram tão profundas; o debate sobre minha experiência em sala com os outros colegas era sempre algo menor, era algo que não carecia de uma reflexão, e isso repercutia nas disciplinas que não eram necessariamente de docência, porque criou-se meio que uma desculpa pra ter poucas disciplinas de docência; a ideia de que toda disciplina vai lhe ensinar a ser professor [...]. (Professor Moreira de Sousa).
\end{abstract}

Quanto a casos dessa natureza, Therrien e Carvalho (2009) nos alertam para os saberes que estão sendo construídos na práxis docente, na ecologia da sala de aula, ressaltando o status epistêmico do professor. Para os autores, a definição de saber

Educ. Form., Fortaleza, v. 6, n. 1, e2885, jan./abr. 2021

DOI: https://doi.org/10.25053/redufor.v6i16jan/abr.2885

https://revistas.uece.br/index.php/redufor/index 
fundamenta-se na concepção de que este é produto da dinâmica de percepção, do julgamento e da argumentação situados em um contexto, sendo, ao mesmo tempo, individual e coletivo, isto é, intersubjetivo. E ainda chamam de saberes de experiência, de saberes práticos, aqueles que são construídos na prática social e pedagógica do cotidiano do professor.

Concluímos os relatos de nossos sujeitos assim como iniciamos, pois uma docente, mesmo afirmando que seu curso era voltado para a formação de professores, ainda assim ressalta a importância da prática cotidiana para a sua formação. Vejamos abaixo:

\begin{abstract}
Eu senti que era mais pra formação de professores mesmo, apesar de que a gente pega uns professores que parecem que nunca tiveram noção do que é sala de aula e fazem com que a gente pense que a educação brasileira é uma maravilha. Mas, como eu já tinha uma certa experiência em sala de aula, aí a gente acabava debatendo muito por conta disso: 'Ah, professora, não é bem assim. A questão não é como a senhora tá falando [...]'. Na verdade, a gente aprende a dar aula na prática mesmo, em sala de aula. Acho que não vai ter nenhum curso que vai dizer assim: 'Ah, você vai dar aula'. Porque, como eu te disse, são cabeças diferentes, então você pode tá preparado pra trabalhar com jovens que sejam bastante receptivos, mas outros já podem encarar tua prática de maneira negativa. Citar o meu cotidiano mesmo: eu tenho quatro turmas de $1^{\circ}$ ano; como eu disse, a turma da manhã eu consigo passar as duas aulas conversando com eles em relação ao conteúdo, já a turma da tarde eu não consigo fazer isso, eles preferem fazer atividade, porque, se eu falar mais do que deveria, já dá sono naquela turma, tá entendendo? Então, a gente aprende a dar aula em sala de aula mesmo [...]. Ensinar a ser professor mesmo só o dia a dia, a experiência que você vai adquirindo com os próprios alunos [...]. Planejo a aula, vejo o conteúdo que eu vou dar, faço as explanações na lousa, as explicações em sala, às vezes levo alguns slides, mas é na hora mesmo que a gente vai construindo a aula, porque eu sei o que eu vou fazer, eu sei o que eu vou falar, mas vai ser na hora que a gente vai mesmo ver como é que vai sair aquilo ali; vai ser dado o andamento daquela situação vai ser na hora, porque vai depender da receptividade dos alunos [...]. (Professora Rachel de Queiroz).
\end{abstract}

O discurso da professora condiz com a definição de Shulman (apud GONÇALVES, T. O.; GONÇALVES, T. V., 1998) de "saber estratégico". De acordo com esse autor, esta seria a capacidade de articular os vários saberes diante de uma situação inusitada no improviso da ação no chão da sala. E Therrien e Carvalho (2009) entendem como saberes da ação docente como sendo aqueles provenientes da ação situada e reflexiva da profissão docente, os quais o professor manipula para enfrentar as situações advindas do seu cotidiano. São saberes que contêm em si os conhecimentos proporcionados à educação pelas ciências humanas, os saberes pedagógicos da interação com os alunos, da elaboração e experimentação de hipóteses de trabalho, até

Educ. Form., Fortaleza, v. 6, n. 1, e2885, jan./abr. 2021

DOI: https://doi.org/10.25053/redufor.v6i16jan/abr.2885

https://revistas.uece.br/index.php/redufor/index 
a reinvenção de técnicas, procedimentos e recursos do seu cotidiano pedagógico. Assim, o saber implica racionalidade, o que evidencia a possibilidade de estudar o saber a partir da fala dos sujeitos, colocando os saberes profissionais como objeto epistêmico. Portanto, o saber docente pode ser definido também como a inteligibilidade do professor mediante os fenômenos. A nossa definição de saber é relativa à razão, aos discursos, aos argumentos, aos juízos, às ideias, que seguem uma exigência da racionalidade. $A$ racionalidade aqui é entendida como uma forma intencional de conceber do sujeito; significa dizer que as pessoas agem não como máquinas, mas em função de objetivos, de projetos, de escolhas, de motivos. Pela peculiaridade da ecologia da sala de aula, esta racionalidade pode ser definida como pedagógica (THERRIEN; CARVALHO, 2009).

\section{Considerações finais}

Os discursos dos professores convergem para pontos em comum, isto é, todos eles apontam lacunas em suas formações referentes ao conhecimento prático, à preparação para o ambiente de sala de aula. Todos ressaltam a grande distância entre teoria e prática presente em seus cursos de graduação e inclusive de pós-graduação.

Em contrapartida, apontam que o fazer diário de seu ofício constitui lócus de formação muito mais eficiente, revelando o caráter formador da prática docente. Essa prática criativa do professor se manifesta no dia a dia das salas de aula, na ação inventiva desse profissional diante das interações dinâmicas da realidade concreta da escola, perante as incertezas das situações complexas vividas nas relações com os alunos. Assim, o professor tem que tomar decisões perante as imprevisibilidades das situações problemáticas concretas, tem de manter um diálogo com tais situações e adotar estratégias adequadas para cada situação, pois cada situação é singular e a ela não se podem aplicar regras preestabelecidas. Por isso, o conhecimento científico que se transmite nas instituições de formação de professores converte-se definitivamente num conhecimento acadêmico, que se aloja não na memória semântica, significativa e produtiva do aluno-mestre, mas apenas nos satélites da memória episódica, isolada e residual nos programas de formação de professores. $O$ fracasso mais significativo reside no abismo que separa a teoria e a prática (WOODS, 1995). 
Considerando assim, corroboramos a ideia do autor de que o professor se defronta em sua vida profissional com uma multiplicidade de situações para as quais não existem respostas pré-elaboradas e que não são passíveis de serem analisadas pela investigação científica clássica. Dessa forma, concluímos que não há realidades objetivas passíveis de serem conhecidas em sua totalidade. As realidades se criam e se constroem no intercâmbio psicossocial da sala de aula, residindo aí a complexidade do ofício de professor e da ação como um paradigma de constituição de saberes.

\section{Referências}

ALVES, W. F. O trabalho dos professores: saberes, valores, atividade. Campinas: Papirus, 2010.

ALVES-MAZZOTTI, J. O debate atual sobre os paradigmas de pesquisa em educação. Cadernos de Pesquisa, São Paulo, v. 96, n. 96, p. 15-23, 1996. Disponível em: http://publicacoes.fcc.org.br/ojs/index.php/cp/article/view/810/820. Acesso em: 5 jan. 2015.

ARAÚJO, F. M. L.; MOREIRA JUNIOR, R. Dilemas e estratégias do professor de História no exercício da docência no ensino médio. In: FARIAS, I. M. S.; NÓBREGA-THERRIEN, S. M.; CARVALHO, A. D. F. (Org.). Diálogos sobre formação de professores: olhares plurais. Teresina: UFPI, 2012. p. 106-118.

BORGES, C. M. Os professores da educação básica de $5^{\underline{a}}$ a $8^{\underline{a}}$ séries e seus saberes profissionais. 2003. 210 f. Tese (Doutorado em Educação) - Programa de Pós-Graduação em Educação, Pontifícia Universidade Católica do Rio de Janeiro, Rio de Janeiro, 2003.

CERTEAU, M. A invenção do cotidiano 1: as artes de fazer. Petrópolis: Vozes, 1994.

D'ÁVILA, C. M.; SONNEVILLE, J. J. Trilhas percorridas na formação de professores: da epistemologia da prática à fenomenologia existencial. In: VEIGA, I. P. A.; D’ÁVILA, C. M. (Org.). Profissão docente: novos sentidos, novas perspectivas. Campinas: Papirus, 2008. p. 23-44.

GAUTHIER, C. et al. Por uma teoria da pedagogia. ljuí: Unijuí, 1998.

GÓMEZ, A. P. O pensamento prático do professor: a formação do professor como profissional reflexivo. In: NÓVOA, A. (Org.). Os professores e sua formação. 2. ed. Portugal: Dom Quixote, 1995. p. 93-114.

GONÇALVES, T. O.; GONÇALVES, T. V. O. Reflexões sobre uma prática docente situada: buscando novas perspectivas para a formação de professores. In: GERALDI, C. 
M. G. et al. (Org.). Cartografia do trabalho docente: professor(a)-pesquisador(a). Campinas: Mercado das Letras: Associação de Leitura do Brasil, 1998. p. 105-133.

MINAYO, M. C. S. O desafio do conhecimento: pesquisa qualitativa em saúde. São Paulo: Hucitec, 2013.

MONTEIRO, A. M. Professores de História: entre saberes e práticas. Rio de Janeiro: Mauad X, 2007.

NÓBREGA-THERRIEN, S. M.; FARIAS, I. M. S.; SALES, J. A. M. Abordagens quantitativas e qualitativas em educação: velhas e novas mediações e compreensões. In: FARIAS, I. M. S.; NUNES, J. B. C.; NÓBREGA-THERRIEN, S. M. (Org.). Pesquisa científica para iniciantes: caminhando no labirinto. Fortaleza: UECE, 2010. p. 53-68.

OLIVEIRA, S. M. S. Formação de professores e ensino de História da África e cultura afro-brasileira e africana: saberes e práticas. 2016. 210 f. Dissertação (Mestrado em Educação) - Programa de Pós-Graduação em Educação, Universidade Estadual do Ceará, Fortaleza, 2016.

SCHÖN, D. A. Educando o profissional reflexivo: um novo design para o ensino e a aprendizagem. Porto Alegre: Artmed, 2000.

TARDIF, M. Saberes docentes e formação profissional. Petrópolis: Vozes, 2012.

TARDIF, M. Saberes profissionais dos professores e conhecimentos universitários: elementos para uma epistemologia da prática profissional dos professores e suas conseqüências em relação à formação para o magistério. Rio de Janeiro: PUC, 1999.

TARDIF, M.; LESSARD, C. O trabalho docente: elementos para uma teoria da docência como profissão de interações humanas. 3. ed. Petrópolis: Vozes, 2007.

TARDIF, M.; LESSARD, C.; LAHAYE, L. Os professores face ao saber: esboço de uma problemática do saber docente. Teoria \& Educação, Porto Alegre, n. 4, p. 215-133, 1991.

THERRIEN, J.; CARVALHO, A. D. F. O professor no trabalho: epistemologia da prática e ação/cognição situada - elementos para a análise da práxis pedagógica. Revista Brasileira de Formação de Professores, Belo Horizonte, v. 1, n. 1, p. 129-147, 2009. Disponível em: http://www.facec.edu.br/seer/index.php/formacaodeprofessores. Acesso em: 2 jan. 2016.

VEIGA, I. P. A.; D’ÁVILA, C. M. (Org.). Profissão docente: novos sentidos, novas perspectivas. Campinas: Papirus, 2008.

WOODS, P. Aspectos sociais da criatividade do professor. In: NÓVOA, A. (Org.). Profissão professor. Porto: Porto, 1999. p. 125-154. 
Sônia Maria Soares de Oliveira, Secretaria de Educação do Estado do Ceará

i- Dhttps://orcid.org/0000-0001-7873-9030

Mestra em Educação e graduada em História pela Universidade Estadual do Ceará (UECE). Tem experiência na área de História, com ênfase em História, especialização em Metodologias do Ensino de História pela UECE. Atua como professora da educação básica na rede estadual de ensino desde 2001, lecionando a disciplina de História no ensino médio.

Contribuição de autoria: Desenvolveu toda a pesquisa, escrita e processo metodológico.

Lattes: http://lattes.cnpq.br/2430534018302814

E-mail: soniasoares_bb@hotmail.com

Fátima Maria Leitão Araújo, Universidade Estadual do Ceará, Programa de Pós-Graduação em Educação

ii:Dhttps://orcid.org/0000-0001-9118-3778

Doutora em Educação Brasileira pela Universidade Federal do Ceará (UFC), mestra em Educação também pela UFC, especialista em História das Ideias Políticas pela Universidade Estadual do Ceará (UECE) e graduada em História também pela UECE. Professora associada da UECE, vinculada ao curso de graduação em História, bem como ao Programa de Pós-Graduação em Educação (PPGE) e ao Mestrado Interdisciplinar em História e Letras (MHIL).

Contribuição de autoria: Revisou e orientou a pesquisa, o estudo e a escrita.

Lattes: http://lattes.cnpq.br/0660621158248890

E-mail: fatima.leitao@uece.br

Carlos Diogo Mendonça da Silva, Universidade Estadual do Ceará, Programa de Pós-Graduação em Educação

iii Dhttps://orcid.org/0000-0002-5522-9262

Bacharel em Psicologia pela Estácio - FIC, formação em Psicoterapia Junguiana pelo Laboratório de Individuação e Reintegração da Totalidade (Labirinto). Concentra interesse de estudo com foco nos seguintes temas: Clínica Junguiana, Psicopatologia Junguiana, Psicologia Pós-Junguiana, Mitologia, Epistemologia das Psicologias, Psicologia Social, Gênero e Sexualidade, Sofrimento Psicossocial, Saúde Mental, Proteção Social e Direitos Humanos.

Contribuição de autoria: Contribuiu na análise dos relatos.

Lattes: http://lattes.cnpq.br/5501156621270694

E-mail: diogomendonca@gmail.com

Editora responsável: Lia Machado Fiuza Fialho Pareceristas ad hoc: Cristina Mandau Cá e Daniel Silva

\section{Como citar este artigo (ABNT):}

OLIVEIRA, Sonia Maria Soares de; ARAÚJO, Fátima Maria Leitão; SILVA, Carlos Diogo Mendonça da. A prática como lócus de produção de saberes: vozes de professores sobre formação inicial e práticas escolares cotidianas. Educ. Form., Fortaleza, v. 6, n. 1, e2885, 2020. Disponível em: https://revistas.uece.br/index.php/redufor/article/view/2885 


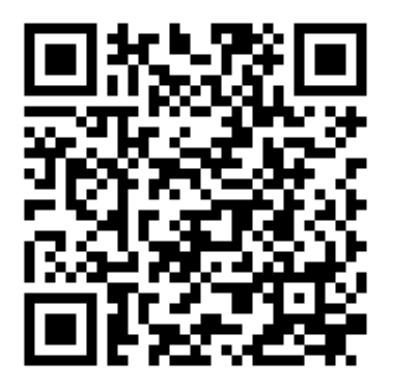

Recebido em 7 de maio de 2020.

Aceito em $1^{\circ}$ de setembro de 2020.

Publicado em 15 de outubro de 2020. 